
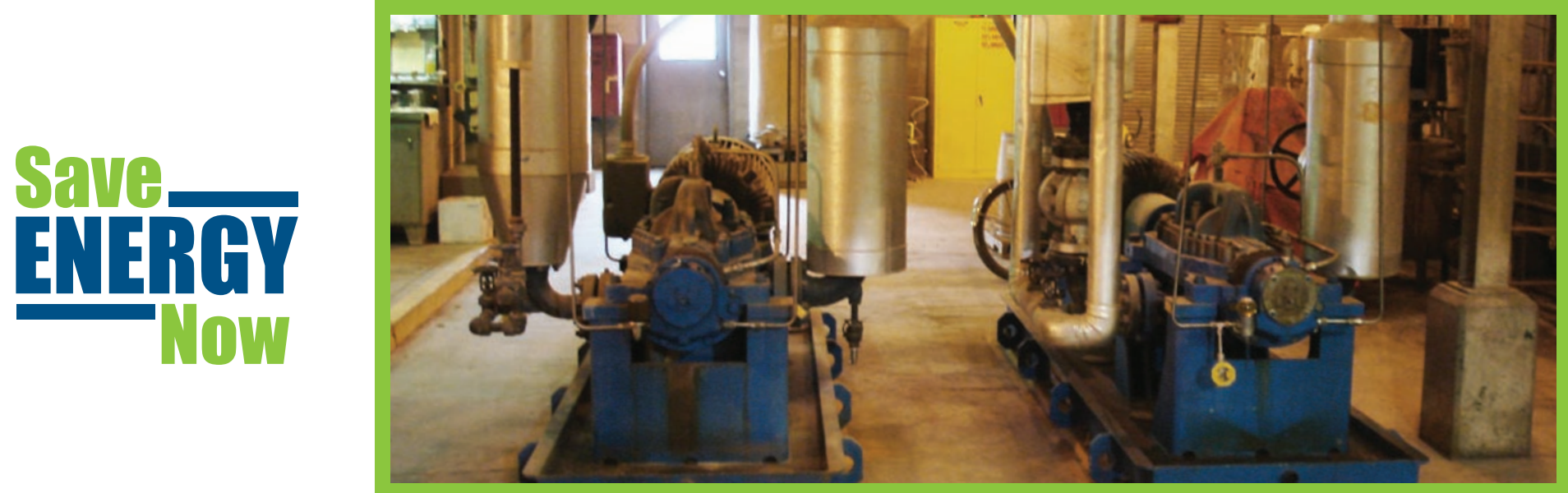

The J.R. Simplot Don plant in Pocatello, Idaho, repaired boiler feed water pumps such as the one pictured above, and revised boiler operating practices to reduce steam venting by 17 million pounds annually.

\title{
Steam System Efficiency Optimized After J.R. Simplot Fertilizer Plant Receives Energy Assessment
}

\section{Benefits}

Implemented \$335,000

in annual energy

cost savings

Saved 75,000 MMBtu in

annual fuel use

Achieved a simple

payback of 6.5 months

\section{Key Findings}

- Significant energy savings can be achieved without large capital expenditures.

- While the J.R. Simplot company had an active energy management program, the Save Energy Now assessment provided fresh insights that led to new energy savings opportunities.

- By improving boiler operation, recovering more condensate, and repairing steam traps and leaks, the plant achieved significant energy savings.

- Once the significance of one energy-saving measure is understood, additional measures are likely to be implemented.

\section{Applications}

Steam systems are widespread in fertilizer plants and can account for a significant amount of end use energy consumption. Improving boiler efficiency and reducing steam loss can result in significant energy savings and improved production.

\section{Summary}

The J.R. Simplot company's Don Plant in Pocatello, Idaho, received a U.S. Department of Energy (DOE) Save Energy Now assessment in 2006. The main objectives of the assessment were to help the plant operate more efficiently by identifying ways to reduce energy use in its steam system. Working with the facility's maintenance engineers, DOE Energy Expert Bill Moir of Steam Engineering Inc., utilized DOE's Steam System Assessment Tool (SSAT) software to identify multiple energy savings opportunities in the plant's steam system. By capitalizing on several of these opportunities, plant personnel were able to improve steam system efficiency and reduce energy consumption.

Plant personnel began implementing some of the recommendations as soon as the assessment was completed. They optimized boiler operation to reduce steam venting, improved condensate recovery, repaired steam traps, and fixed steam leaks. As a result, the plant realized total annual cost savings of $\$ 335,000$, and energy savings of more than 75,000 MMBtu. With project costs of approximately $\$ 180,000$, the plant achieved a simple payback of approximately 6.5 months. Some of the other opportunities identified in the assessment are under consideration and the results were also shared with employees from other J.R. Simplot plants. 


\section{Project Drivers}

Energy efficiency is an important part of the J.R. Simplot company corporate culture. Mr. J.R. Simplot, the founder of the company who passed away on May 25, 2008, at the age of 99, was highly supportive of energy efficiency and of the employees' efforts to reduce energy consumption. As a result, employees at the company's Don Plant are always looking for opportunities to reduce energy use. During the Save Energy Now post-assessment presentation, many of the employees were surprised by how much steam was being vented unnecessarily. This led them to investigate the feasibility of reducing the amount of vented steam. After determining that this project would be cost-effective, they quickly took the necessary steps to get it done. This then motivated them to take additional action and capture other energy savings opportunities identified during the assessment.

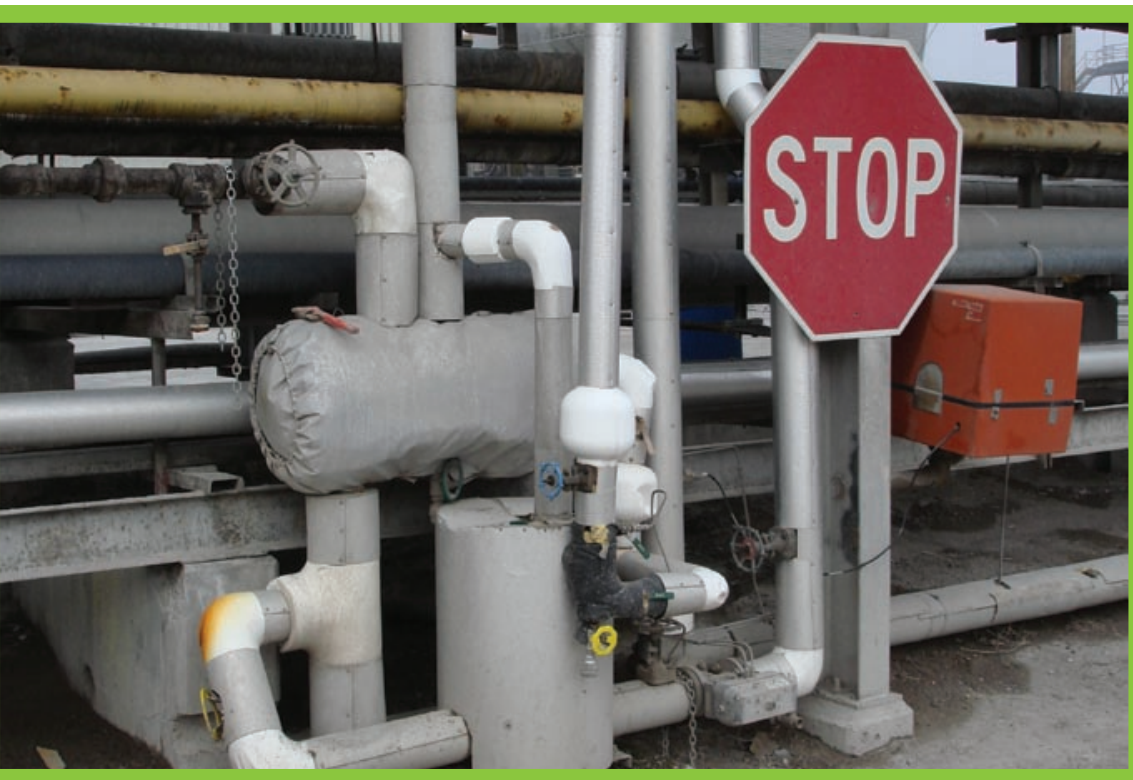

Following the Save Energy Now assessment, plant personnel repaired the medium pressure condensate line and the pumps serving it, including the pump pictured above, for a $15 \%$ increase in the condensate recovery rate and an annual reduction of 3 million gallons in water consumption.

\section{Company and Plant Background}

The J.R. Simplot Company is a major food and agribusiness corporation based in Boise, Idaho, with annual sales of around $\$ 3$ billion. The company has more than 10,000 employees in the United States, Canada, China, Mexico, and Australia. Simplot's business activity includes the production of food, fertilizer, turf, and horticultural products; cattle feeding; and other agribusiness enterprises. Commissioned in 1944 and located just outside Pocatello, Idaho, the Don plant is one of four fertilizer plants in the J.R. Simplot Company's Mining and Manufacturing Group. These facilities are located throughout the Western United States and focus on producing high-quality fertilizers and distributing agricultural products.

The Don plant produces more than 1 million tons of phosphate fertilizers, feed phosphates, and related industrial products annually. The facility burns sulfur to produce sulfuric acid for its fertilizer production process and captures the heat from sulfuric acid production to generate steam. Most of the plant's steam is generated in two heat recovery boilers fired by the sulfur in acid plants \#3 and \#4. The steam from plant \#3 is used to drive a turbine powered blower, and the steam from plant \#4 is used to generate electricity from a steam turbine generator set. Exhaust steam from these two turbines is used for process heat. This process steam is supplemented when necessary with two natural gas-fired utility boilers.

\section{Assessment Overview}

The assessment at the Don plant was performed by a DOE Energy Expert who is a qualified specialist on the use of DOE's SSAT software. The expert formed an assessment team with six of the plant's employees and installed the SSAT on their computers. Together, they reviewed the results from the Steam System Scoping Tool along with some plant-specific information to begin the modeling process. They toured both acid plants and the boiler control room to observe the operation of two steam turbines and the pressure reducing stations. Prior to the assessment, the plant commissioned a steam trap survey as part of its energy management program, which provided valuable data for the SSAT model. 
After finalizing the data collection, the assessment team generated several opportunities using the SSAT and classified them based on expected energy savings, technical and economic feasibility, and the following payback periods: near-, medium-, and long-term.

\section{Near-term opportunities}

- Reduce Vented Steam-The plant balances its steam load by operating natural gas-fired utility boilers when the plant load exceeds the capacity of the two acid plants. Under certain conditions excess steam is vented to atmosphere to maximize sulfuric acid production. The assessment concluded that this steam could be used for process steam, replacing steam generated by the utility boilers. This would result in a $10 \%$ reduction in vented steam that could reduce energy consumption by $64,000 \mathrm{MMBtu}$ and save $\$ 295,000$ annually.

- Implement Steam Trap Repairs - By inputting data from the recently completed steam trap survey into the SSAT, the assessment team determined that annual energy savings of 21,000 MMBtu and \$98,000 were feasible from repairing the plant's failed steam traps.

- Implement Steam Leak Repairs - The assessment team performed a steam leak survey and extrapolated the data to determine the leak load on the plant's headers. Using the SSAT, they calculated that repairing these leaks could yield annual energy savings of more than 12,600 MMBtu and \$59,000.

\section{Medium-term opportunities}

- Reduce Steam Demand-The natural gasfired utility boilers needed to run to maintain their proper operating temperature during periods of low steam demand. During these periods of operation, the boilers used natural gas while steam was being vented by the recovery boilers. The assessment suggested that the plant use flash steam to maintain their proper operating temperature by installing drum heaters in the utility boilers. This would reduce utility boiler natural gas use by $5 \%$, yielding annual natural gas and cost savings of 27,000 MMBtu and \$182,500.

\section{- Increase Condensate Recovery-Some of} the plant's condensate was not recovered due to malfunctioning pumps and worn piping in the medium pressure condensate recovery system. This led to greater than necessary consumption of water and energy. By repairing the condensate line and pumping stations, $15 \%$ more condensate could be recovered, which would result in annual water and energy savings of 3.7 million gallons and more than 10,000 MMBtu. It would also save \$83,000 annually.

- Improve Insulation-The assessment demonstrated the use of DOE's 3E Plus ${ }^{\circledR}$ software to determine heat losses in the plant's headers, including how to calculate potential energy savings from properly insulating the un-insulated portions of pipe. Plant personnel decided to perform the survey on an ongoing basis and insulate any under-insulated header sections in the future.

\section{Long-term opportunity}

\section{- Install Back Pressure Steam Turbine} Generator-The Don plant lowers highpressure steam into the lower pressure headers with a pressure reducing valve (PRV) in acid plant \#3. By replacing this PRV with a back pressure turbine generator, the plant could generate electricity, thereby saving energy and offsetting required electricity purchases. The assessment's analysis showed the back pressure turbine could also extract energy from the process steam and further reduce steam venting, which could save the plant almost 4,000 MMBtu and more than 51 million $\mathrm{kWh}$ annually. Total cost savings would be approximately $\$ 1.7$ million per year.

If implemented, the total annual energy cost savings from these measures was estimated at more than $\$ 2.5$ million.

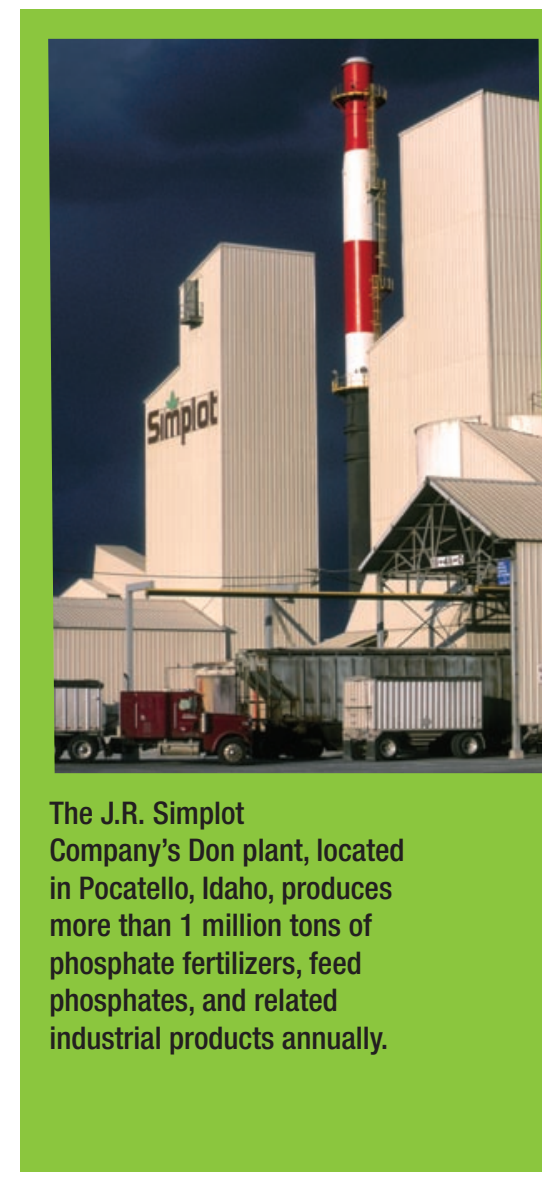




\section{Results}

Personnel systematically improved the efficiency of the Don plant's steam system. They began repairs on the failed steam traps and on some of the leaks in the headers even before the assessment was completed. Following a presentation to the plant's management, they revised their boiler operating practices to reduce steam venting by 17 million pounds annually. The plant also had the boiler feed water pumps repaired, which is yielding significant energy savings. Finally, they repaired the medium pressure condensate line and the pumps serving it. This has led to a $15 \%$ increase in the condensate recovery rate and a reduction in annual water consumption of more than 3

"Thanks to the Save Energy Now assessment, the company is more efficient and no longer wasting steam. We have done steam trap maintenance that has improved our recovery of condensate throughout the plant and we have also changed some operations. We were running boilers every shift to keep them hot and just venting the steam. The assessment determined we didn't need to do that." - Paul Malek, Area Manager, J.R. Simplot Don Plant million gallons.

Plant employees investigated the possibility of installing drum heaters on the utility boilers and a back pressure steam turbine generator in acid plant \#3, but determined that they would not meet the company's payback criteria. Total annual savings from the implemented measures are more than $\$ 335,000$ in costs and 75,000 MMBtu in energy. Because the project's total costs were $\$ 180,000$, the plant achieved a payback of just 6.5 months. Since the completion of the project, employees at the Don plant developed additional tracking tools, protocols, and efficiency measures based on the SSAT software and the methodology they gained from the Save Energy Now assessment. These insights are being shared with other Simplot facilities.

\section{Lessons Learned}

Successful energy efficiency improvements can serve as catalysts for implementing additional efficiency measures. At J.R. Simplot's Don plant, assumptions about steam requirements for sulfuric acid production led to unnecessary steam venting. When plant personnel realized they could reduce steam venting without having a negative impact on production, they were motivated to take additional steps to improve the efficiency of the steam system. In the wake of the success of the steam venting reduction, employees placed a renewed emphasis on improving the efficiency of the plant's steam system.

This realization was made possible by the presentation using the SSAT analysis. SSAT and other DOE software tools such as AIRMaster+, the Fan System Assessment Tool (FSAT), MotorMaster+, the Process Heating Assessment and Survey Tool (PHAST), the Pumping System Assessment Tool (PSAT), and 3E Plus can similarly be used to analyze industrial systems and processes and generate energy efficiency opportunities.

\section{About Save Energy Now \\ Through Save Energy Now, DOE's Industrial Technolo- gies Program (ITP) helps industrial plants operate more efficiently and profitably by identifying ways to reduce energy use in key industrial process systems. Visit www.eere.energy.gov/industry/saveenergynow for more information.}

\begin{abstract}
A Strong Energy Portfolio for a Strong America
Energy efficiency and clean, renewable energy will mean a stronger economy, a cleaner environment, and greater energy independence for America. Working with a wide array of state, community, industry, and university partners, the U.S. Department of Energy's Office of Energy Efficiency and Renewable Energy invests in a diverse portfolio of energy technologies.
\end{abstract}

For more information, contact the EERE Information Center, 1-877-EERE-INF (1-877-337-3463), www.eere.energy.gov And visit the DOE Industrial Technologies Program home page: www. eere.energy.gov/industry 